\title{
Aproximación a la equidad en salud en perspectiva de dignidad: notas para una bioética social
}

\author{
Approach to equity in health in perspective \\ of dignity:
}

notes for a social bioethics

Aproximação à equidade em saúde em

perspectiva de dignidade:

notas para uma bioética social

Fecha de recepción: 15 de marzo de 2017

Fecha de evaluación: 24 de julio de 2017

Fecha de aceptación: 31 de octubre de 2017

Disponible en línea: 21 de noviembre de 2017

María Teresa Escobar-López*

José Antonio García-Pereáñez ${ }^{* *}$

Fabio Aurelio Rivas-Muñoz ${ }^{* * *}$

\author{
Cómo citar: \\ Escobar-López, M. T., García-Pereáñez, J. A. y Ri- \\ vas-Muñoz, F. A. (2018). Aproximación a la equi- \\ dad en salud en perspectiva de dignidad: notas \\ para una bioética social. Revista Latinoamericana de \\ Bioética, 18(1), 172-190. \\ Doi: https://doi.org/10.18359/rlbi.3161
}

* Odontóloga, Universidad Nacional de Colombia y doctora en Bioética, Universidad El Bosque. Profesora titular de la Universidad Militar Nueva Granada, Bogotá, Colombia. Correo electrónico: maria.escobar@unimilitar.edu.co

** Filósofo, Universidad de Antioquia y doctor en Bioética, Universidad El Bosque. Profesor titular Universidad de Antioquia, Medellín, Colombia. Correo electrónico: jantonio.garcia@udea.edu.co. ORCID: https://orcid. org/0000-0002-9078-1511.

*** Médico, Universidad Nacional de Colombia y doctor en Bioética, Universidad de Brasilia, Brasil. Profesor asociado de la Universidad Nacional de Colombia, Bogotá. Correo electrónico: farivasm@unal.edu.co 
Este escrito aborda la perspectiva sanitaria, en lo fundamental mercantil, por la cual se rigen los destinos de la salud en todo el mundo desde los últimos años del siglo XX, a partir de unas apreciaciones de Philip Musgrove, exfuncionario del Banco Mundial (BM) y exeditor de Health Affairs. Musgrove fue uno de los protagonistas en la elaboración del informe que terminó poniendo la salud abiertamente en manos del BM. Su visión de la salud era esencialmente economicista e individualista, e hizo a un lado cualquier mirada a la dignidad de los seres humanos, así se trate de un término que, como el amor o la belleza, sea de difícil definición, pero de importancia fundamental para la reflexión en bioética social. Se inicia este artículo con un breve recorrido alrededor de este concepto, para luego conectarlo con la estrategia de búsqueda y reducción de inequidades en salud, la cual resulta coherente con la mirada a los determinantes sociales, según el informe final de la comisión nombrada para este asunto. También se ofrece otra mirada para la reflexión sobre la equidad en salud, según los referentes entre la calidad de vida y el bienestar.

Palabras clave: dignidad, justicia, determinantes sociales, salud pública, bioética social.

\section{Abstract}

The paper addresses the health perspective, fundamentally commercial, which governs the health destinations around the world since the last years of the twentieth century, from an assessment of Philip Musgrove, a former World Bank (WB) official and former editor of Health Affairs. Musgrove was one of the protagonists in the preparation of the report that ended up putting health openly in the hands of the World Bank. His vision of health was essentially economistic and individualistic and set aside any glance at the dignity of human beings, whether it is a term that, like love or beauty, is difficult to define, but of vital importance for reflection in social bioethics. This article begins with a brief tour around this concept, and then connects it with the search strategy and reduction of inequities in health, which is consistent with the look at the social determinants, according to the final report of the commission appointed for this affair. Another look is also offered for reflection on equity in health, according to the referents between the quality of life and well-being.

Keywords: Dignity, justice, social determinants, public health, social bioethics.

\section{Resumo}

Este artigo aborda a perspectiva sanitária, no fundamental comercial, pela qual se regem os destinos da saúde em todo o mundo desde os últimos anos do século XX, a partir de umas apreciações de Philip Musgrove, ex-funcionário do Banco Mundial (BM) e ex-editor de Health Affairs. Musgrove foi um dos protagonistas na preparação do relatório que acabou colocando a saúde abertamente nas mãos do BM. Sua visão da saúde era essencialmente economicista e individualista, e fez a um lado qualquer olhar para a dignidade dos seres humanos, assim trate-se de um termo que, como o amor ou a beleza, seja difícil de definir, mas de fundamental importância para a reflexão em bioética social. Este artigo começa com um breve passeio em torno deste conceito, para depois conectá-lo com a estratégia de busca e redução de desigualdades em saúde, o que é consistente com o olhar a os determinantes sociais, de acordo com o relatório final da comissão nomeada para este assunto. Também é oferecido outro olhar para a reflexão sobre a equidade em saúde, de acordo com os referentes entre qualidade de vida e o bem-estar.

Palavras-chave: dignidade, justiça, determinantes sociais, saúde pública, bioética social. 


\section{Introducción}

Philip Musgrove (2006) afirmaba: "En salud no se gasta, se invierte" (p. 41). Para este autor, habría dos formas de financiar la salud de los pueblos: prepago y gasto de bolsillo. Cualquiera de las dos apunta al cubrimiento individual de la atención en salud, lo cual resulta muy coherente con el título del artículo, fuente de la frase de este economista: ¿cuánta salud puede comprar un dólar?

Aunque la vigésima segunda edición del Diccionario de la Lengua Española no hace una clara distinción entre gastar e invertir, quienes saben de finanzas sí que la tienen perfectamente clara: contrario a gastar, invertir es un buen negocio. Habría que deducir, siguiendo a Musgrove, que, por invertir en ella, la salud es un buen negocio. Desde la óptica de las aseguradoras, hoy cuando vivimos la hegemonía de los sistemas privados de salud, sin duda esta última es un excelente negocio; por ejemplo, mientras se cierran hospitales en Colombia, realidad que no dista en nada a la de los países bajo la óptica del neoliberalismo, es decir, el denominado Occidente, las aseguradoras, en su mayoría pertenecientes a los grupos macro económicos que manejan la economía mundial, no tienen problemas, o los tienen en ámbitos que no afectan mayormente sus ingresos. Ahora bien, quizá la diferencia entre prepago y gasto de bolsillo no sea muy grande, con cualquiera de ellas está haciéndose una inversión o un gasto, depende de la intención de quien pone el dinero.

Pareciera que para Musgrove, el prepago es una inversión y el de bolsillo, en cambio, un gasto. Sin embargo, el prepago puede ser un gasto más lento, y habría que deducir que una diferencia entre inversión y gasto es la velocidad con que ocurre el desembol- so. Cualquiera que sea la verdad acerca de la perspectiva de este experto en economía de la salud (recientemente fallecido) el planteamiento es uno de naturaleza esencialmente económica, lo cual es también muy coherente con la perspectiva del Banco Mundial, agencia para la cual trabajó Musgrove.

Haber vuelto de la salud una mercancía está en el centro de la siguiente reflexión acerca del concepto de dignidad humana, pues tal transformación simplemente la excluye. Kant sostenía que los seres humanos tenemos dignidad y no precio; sin embargo, los poderosos tras la economía de mercado han decidido todo lo contrario: los seres humanos ocasionamos tantos gastos que lo más eficiente por conseguir es tratar de convertirlos en inversión, así no resultaremos malos negocios. Invierte en tu propia salud porque de ella tú eres el principal responsable parece ser la consigna central en el campo sanitario de un tiempo a esta fecha. El mensaje finalmente es uno y nada más: quien debe invertir o gastar en salud es el individuo porque, es claro, el Estado no se hará cargo.

La reflexión parte del concepto de dignidad el cual, de entrada, ha sido y es bastante complejo. Luego se aborda la inequidad en salud a partir de la propuesta hecha a comienzos de los años 90, por parte de la Organización Mundial de la Salud (OMS) en su versión más reciente, la cual se centra en los llamados determinantes sociales. Estos focos de interés se contextualizan en la globalización y el mercado para abordarse finalmente desde la perspectiva bioética.

De eso trata este escrito, de hacer énfasis en la dignidad como soporte de la justicia en salud, así las argumentaciones desde la gerencia o la economía sanitarias sean importantes y hoy pesen mucho más que 
cualquier otra consideración en la llamada toma de decisiones en "política pública". Esta es otra expresión que surge precisamente en tiempos cuando "la iniciativa privada" se asocia con lo mejor, lo más abierto y transparente, lo que permitirá salir del atraso y nos llevará por los caminos del progreso.

\section{Dignidad}

Desde sus orígenes, para el cristianismo y otras religiones monoteístas, los seres humanos somos semejantes (Gómez, 2008); esto es, diferentes de otros seres vivos en el planeta. Como semejantes, somos dignos de igual consideración y respeto, razón por la cual no cabe la existencia de seres humanos dignos y no dignos, ni tampoco la de unos más dignos que otros, porque la dignidad es una sola y está presente desde el momento cuando venimos a la vida; para algunos, aun antes de nacer. Ya la categoría humanos (una identidad que nos distingue de los animales) nos hace merecedores de esa consideración y respeto. Nos identificamos como humanos aunque pertenezcamos a diferentes culturas, profesemos diversas religiones, miremos la vida desde ópticas variadas y definamos lo bueno o lo malo desde diferentes posturas. La dignidad quizá sea uno de los pocos universales a los que podemos acudir en estos tiempos, cuando el énfasis en el discurso de la democracia occidental está puesto en la diversidad o la pluralidad, eso sí, sin profundizar en asuntos relacionados con la redistribución, el reconocimiento y la representación de la que habla Nancy Fraser (2008) al abordar un asunto estrechamente relacionado con el concepto de dignidad de los seres humanos: la justicia.

Fraser (2008), en su texto, Escalas de justicia, refiere al comienzo del capítulo 2 que: "El asunto es que con la globalización los Estados perdieron protagonismo y las relaciones ya no son únicamente entre conciudadanos al interior de las unidades estatales nacionales" (s. p.). Si bien la redistribución (de recursos) y el reconocimiento (de la diversidad) son fundamentales hacia la justicia social, la autora introduce en este texto la representación (por ejemplo, de las llamadas minorías en los organismos de gobierno) como criterio fundamental, a fin de que la diversidad tenga un lugar en "la mesa de negociaciones" en busca de dicha justicia social.

Como ya se refirió, un punto de partida es ver la dignidad como un merecimiento de todos los seres humanos por el único hecho de serlo. Ahí radicaría lo universal del concepto. No importa el tipo de vida que llevemos, la condición social o económica sobre la que transite nuestro paso por la Tierra, la visión o las creencias por las que nos inclinemos o nos fueron inculcadas, tenemos dignidad.

Si bien, de tiempo atrás, la consideración de digno también está ligada con la consideración de libre, esta última tampoco puede reducirse al principio de autonomía que resalta la visión anglosajona de la bioética, surgida, como se sabe, en el contexto de la salud centrada en el individuo, principalmente del occidente desarrollado del mundo, un humano que pareciera requerir únicamente información clara y completa para tomar una decisión autónoma. La autonomía, aun en perspectiva individual, pide mucho más que información y se puede llegar a ser autónomo incluso con información poco clara o incompleta, cosa muy frecuente hoy, ${ }^{1}$ cuando

1 Ver investigaciones base de esta reflexión por parte de Escobar López y Carrera Celis, M, (2015), Sáenz Cortés, Escobar López y Aristizábal Tobler (2016) y Escobar López y Novoa Torres (2016) es- 
(¡nuevamente!) los poderosos del libre mercado del mundo manipulan información acerca de hechos, recientes o históricos, y estadísticas para lograr recuperar prontamente sus inversiones o acceder a nuevos negocios. Por otro lado, aun con toda la información, o al menos con suficiente información al respecto, puede ocurrir que no consigamos tomar una decisión autónoma debido a condiciones más allá de la información disponible y que obligan a inclinarnos a favor de una opción menos satisfactoria. Suele suceder esto con los tratamientos odontológicos que, en su mayoría, están excluidos de los sistemas de aseguramiento, y en los cuales finalmente la decisión se toma con base en el dinero de bolsillo o acudiendo a la propia capacidad de endeudamiento.

Juliana González, de la Universidad Autónoma de México, citando la Enciclopedia de Bioética, refiere: "pocos términos o ideas son más centrales para la bioética y son menos claramente definidos que el de dignidad humana" (2008, p. 277). Sin duda, la perspectiva anglosajona de la bioética hace eco de la dignidad cuando promueve la protección de los sujetos vulnerables, tanto en la atención como en la investigación en salud, puesto que no por ser vulnerables tienen menos dignidad. Entonces, a pesar de lo poco claro de cualquier definición, la dignidad hace parte del interés de la bioética. Por ejemplo, una persona que sufre de retraso mental es vulnerable, pero digna de consideración y respeto, igual una persona que padece Alzheimer. Sin embargo, ¿no son acaso vulnerables los millones de seres humanos que habitan las barriadas pobres de las ciuda-

tudios históricos, de percepción en pacientes y profesionales y revisión sobre consentimiento informado donde se verifican las múltiples falencias al respecto. des en nuestros países, a quienes afecta cada una de las decisiones que expertos en "política pública" toman desde sus escritorios en los organismos oficiales y privados?, ¿por qué tales políticas no pueden considerarse experimentos masivos con seres humanos $y$, por consiguiente, someterlas previamente al rigor de una evaluación ética, como se hace con un protocolo de investigación en una universidad u otra institución científica?

La misma autora refiere que, para algunos, la dignidad es respeto mutuo, entendiendo el respeto como "mirar de nuevo", "mirar desde dentro y hacia dentro", "desde la propia humanidad hacia la humanidad del otro" (2008, p. 278). ¿No luce un irrespeto al ser humano aceptar que muera un millón de personas anualmente a causa de una enfermedad como la malaria, para la cual hay reconocidas medidas de prevención y control, evaluadas y avaladas por la más reciente innovación en el ámbito sanitario: la salud pública basada en evidencias? ${ }^{2}$, teniendo en cuenta que

La salud pública basada en la evidencia es la ejecución y la evaluación de la efectividad de intervenciones, planes, programas, proyectos y políticas en salud pública a través de la aplicación de los principios de razonamiento científicos, incluyendo el uso sistemático de datos y sistemas de información. (Hernández, 2003, p. 40.)

Así las cosas, ¿es que el acceso equitativo a la atención en salud no es un asunto de digni-

2 "La salud pública basada en la evidencia es la ejecución y la evaluación de la efectividad de intervenciones, planes, programas, proyectos y políticas en salud pública a través de la aplicación de los principios de razonamiento científicos, incluyendo el uso sistemático de datos y sistemas de información" (Hernández, 2003, p. 40). 
dad o respeto mutuo más que de economía, o al menos tan importante como esta?

El referido Diccionario Latinoamericano de Bioética muestra que la dignidad también ha sido abordada en perspectiva de solidaridad. A ese respecto, Barchifontaine (2008) aporta algo interesante, pues define la solidaridad como "ese lazo recíproco que une personas como corresponsables por el bien de los demás" (p. 278). A partir del respeto, pudiera comprenderse mejor el sentido de la solidaridad. Ese mirar nuevamente puede entenderse como "te miro y en ti me miro"; por tanto, surge la solidaridad si, por ejemplo, miro que sufres, sientes dolor, sientes pena. La solidaridad surge cuando sentimos la llamada del sufrimiento del otro; por consiguiente, tiene alguna cercanía con la vulnerabilidad de la que se habló unas líneas atrás. En algunas constituciones, entre ellas la colombiana, la solidaridad aparece como un deber, por ende, también un derecho. Sin embargo, no puede decirse esto con respecto a la dignidad, pues, como tal, la dignidad no se reclama, aunque sin ella no hay derechos que reclamar, ni ante quién reclamarlos. Es claro entonces lo que afirman Vial-Correa y Rodríguez-Guerrero (2009): "Esa dignidad propia del hombre no existe en grados diversos. Sería absurdo decir que los hombres son más o menos explotables, más o menos usables, como se pueden usar las cosas en general. Esa dignidad "nuclear" o fundamental se tiene o no se tiene" (p. 55).

La dignidad, finalmente, también tiene relación con aquello conocido como cubrimiento de necesidades básicas, las cuales, de no satisfacerse, llevan al daño, se perjudica a alguien y se compromete la propia supervivencia de un ser humano. Por tanto, la cuestión del sujeto digno de consideración y de respeto implica que la sociedad garanti- ce la satisfacción de esas necesidades básicas, aunque no se requiera que tal sujeto sepa que son necesidades y tampoco que son básicas, es decir, aunque no disponga de información sobre este asunto (Rodríguez del Pozo, 1998).

Ahora bien, unos párrafos atrás se hablaba de "sentir", lo cual trae consigo algo fundamental en cuanto a la dignidad del ser humano: la indignación, esto es, el rechazo y la aversión que ocasiona en nosotros (io en algunos de nosotros!) la degradación del valor de otros seres humanos, no importa quiénes sean o dónde estén, es decir, el atropello a su dignidad. En el nacimiento mismo de la bioética, la indignación que produjeron los atropellos contra seres humanos en los campos de concentración nazis, o la que ocasionó la segregación racial en países como Estados Unidos, jugó un papel de importancia tanto como la medicalización de la vida o la revolución científico-técnica, que permitió manipular el ADN. La indignación hace parte de esos indefinibles que recaen en el sentir de las personas, como la salud misma, la belleza o el amor, pero no por eso ha sido irrelevante en las transformaciones sociales a lo largo de la historia de la humanidad. Por estos tiempos hemos sido testigos de varios movimientos a lo largo y ancho del planeta, uno de ellos se hace llamar "indignados" y precisamente ha surgido a raíz de la degradación a la que se ha sometido a las personas en una sociedad que privilegia el tener sobre el ser. "La era de la globalización se caracteriza por el abismo creciente entre ricos y pobres donde se aprecia que el $5 \%$ de los más ricos del mundo reciben 114 veces el ingreso del 5\% de los más pobres" (Tujan, 2007, p. 51). En lo fundamental, están indignados porque las víctimas de la crisis económica por la que atraviesa Europa, España en particular, es decir, las clases medias y bajas, son precisamente 
las que deben hacer el sacrificio, a fin de que esa era de la globalización siga a salvo y esas 114 veces más de ingresos de los privilegiados continúen aumentando.

\section{Inequidad en salud}

Según citan Barbosa y Azevedo Barros (2002, p.376), Rousseau veía las desigualdades entre los seres humanos considerando dos tipos: unas naturales o físicas y las otras morales o políticas. Resulta muy interesante que juntara lo moral y lo político, hoy tan separados. Pero también es interesante que viera la salud como una desigualdad natural, cosa que hoy no luce sostenible si tenemos en mente aquello de los determinantes sociales de la salud, acerca de lo cual la OMS publicara recientemente el informe final de una comisión conformada para abordar estos asuntos (2009). Igualmente, llama la atención que considerara lo moral y lo político como un acuerdo o consentimiento entre los seres humanos. Los autores mencionados también refieren que para Weber las llamadas desigualdades sociales estaban basadas en las relaciones entre riqueza, prestigio y poder. En ocasiones, sobre todo en países en Latinoamérica, se puede ver que tanto riqueza como prestigio y poder están todos juntos en manos de unos cuantos.

El concepto moderno de dignidad humana "no niega la existencia de desigualdades entre los individuos. Lo que sí niega es que esas desigualdades naturales y sociales sean la justificación de un tratamiento desigual por parte de las instituciones o un trato degradante entre los individuos" (Pelè, 2005, p. 9). Desde una perspectiva como esta, se puede enlazar el concepto de dignidad, por vago que sea, con el actual abordaje de la justicia en salud a partir de una importante definición de inequidades, introducida en la última década del pasado siglo. Según refiere Margarite Whitehead (1992). ${ }^{3}$ las inequidades no son simples desigualdades, sino que deben, para considerarse como tales, ser innecesarias y evitables, lo cual, volviendo a Rousseau, las haría moral y políticamente inaceptables. En ese sentido, por ejemplo, que haya diferencias, claras a simple vista, entre hombres y mujeres no es una inequidad, pero, si por el hecho de ser mujer se recibe un salario menor que el de los hombres en el mismo trabajo, hay una inequidad. La mortalidad infantil en el mundo muestra grandes diferencias entre países y regiones de país, así como la mortalidad materna y perinatal. Este sería otro ejemplo de inequidad por cuanto se trata de una diferencia innecesaria y evitable, dado que, con el avance en materia de intervenciones efectivas, se pueden reducir esas muertes a fin de colocarlas en los niveles de países o regiones desarrollados. Visto así el asunto, la equidad en este campo sería un problema de investigación, ciencia y tecnología, más que de política social; esto no es completamente cierto, por cuanto hay evidencia histórica de que el mejoramiento de las condiciones de vida, el acceso al agua potable y la educación (ipolíticas sociales!) jugaron un papel protagónico en la reducción de problemas de salud pública como la mortalidad por tuberculosis en Inglaterra y Gales entre 1840 y 1970, reducción que comenzó a verificarse mucho tiempo antes de la introducción de la quimioterapia (Evans, Barer y Marmor, 1996, p. 12).

3 Ser evitables e innecesarias definen el concepto de inequidades en salud, concepto sobre el cual se sustenta la estrategia de la OMS y el Banco Mundial para afrontar la creciente injusticia sanitaria en el mundo y muchas de las llamadas metas del milenio (Whitehead, 1992). 
Desde la óptica científico-tecnológica, los sistemas de salud deberán ocuparse de medir inequidades en la mira de alcanzar la anhelada justicia en salud; eso precisamente se trata de hacer. La idea central de la estrategia consiste en identificar inequidades en salud, para establecer medidas efectivas tendientes a reducirlas. Se trata de medidas que, a juicio de expertos, en lo fundamental administradores o economistas en salud, epidemiólogos y salubristas, resultan más efectivas, eficaces y eficientes. ${ }^{4} \mathrm{El}$ asunto, en consecuencia, recae en identificar tales inequidades y encontrar la estrategia o estrategias que mejores resultados, es decir, aquellos científicamente válidos, han mostrado en la mira de reducirlas. Esto, sin duda, exige consideraciones económicas que son, de suyo, también éticas. Por ejemplo, se debe tratar de ser justos en la priorización de intervenciones y ello requiere no desperdiciar recursos en acciones que pocas perspectivas tengan de dar resultados. Sin embargo, aparecen problemas cuando la toma de decisiones se basa casi exclusivamente en criterios de carácter económico o en visiones de expertos en esos campos que muy poco o nada consideran elementos más allá de su experticia.

La estrategia de reducción de inequidades en salud surge de una visión experta, esencialmente cuantitativa o mensurable, a sí misma considerada "objetiva"; visión que,

4 Tres términos que apuntan al carácter de "lo mejor" en la perspectiva económica. Según Karen Mokate, en Eficacia, eficiencia, equidad y sostenibilidad: ¿Qué queremos decir? (2002), "Un programa es eficaz si logra los objetivos para que se diseñará. Una organización eficaz cumple cabalmente la misión que le da razón de ser". La autora afirma que eficacia y efectividad son sinónimos y se pueden utilizar en forma intercambiable. Agrega que la eficiencia tiene que ver con cumplir los objetivos al menor costo posible. Establece entonces una "relación entre costos y productos obtenidos". a su vez, es la más extendida en tiempos de globalización, ${ }^{5}$ cuando los indicadores numéricos resumen la verdad acerca de la manera como se nace, se vive, se goza, se sufre y se muere en las diferentes poblaciones humanas. Si la economía de la salud es hoy el eje alrededor del cual debe girar la salud pública y "[...] la sustentabilidad económica y la justicia social a menudo se perciben como amigos incómodos, en el mejor de los casos" (Gosta, Duncan, Hemericjck y Myles, 2006, p.), poca probabilidade tiene la reconocida estrategia de búsqueda y reducción de inequidades en salud de conseguir, por ejemplo, las hoy en boga metas del milenio. En consecuencia, la filantropía (caridad) surge como alternativa de intervención ante el avance de la pobreza. Si usted quiere ser más efectivo que el Estado para solucionar un problema, llámese inequidad en salud, done, no importa si su donación es en dinero o en especie. Es en ese marco donde se inscribe, verbi gracia, el fondo global que tratará de reducir la inequidad en el mundo en materia de VIH, malaria y tuberculosis, una estrategia vertical, esto es, desde arriba, financiada también con donaciones.

Como salida, la perspectiva propuesta y puesta en marcha desde finales del siglo XX en el mundo, de búsqueda y reducción de inequidades en salud, continúa esperanzada en que la ciencia o la técnica traerán la justicia en este campo, bajo el dominio de las llamadas leyes del mercado, donde las donaciones también hacen parte del portafolio de servicios de los poderosos, tras su dinámica y "supuestas" leyes. La epidemiología, precisamente, basa su método en la búsqueda de desigualdades,

5 Mirada a profundidad, la globalización que se está viviendo, esto es la real no la formal, es el libre flujo de dinero y mercancías en todo el mundo. Es precisamente en el marco de esta globalización donde la salud pública se ha visto desplazada por la economía de la salud. 
pues es a partir de ellas que trata de establecer asociaciones entre una o varias exposiciones y uno o varios problemas de salud. Bajo la mirada de inequidades, la salud pública tiene en la epidemiología su mejor herramienta y por esa razón ha sido nominada como la ciencia de la salud pública, algo que tampoco es del todo cierto, al menos es discutible, aunque no en este escrito. No debe olvidarse, sin embargo, que por más eficaces, eficientes y efectivas que resulten algunas intervenciones en los escenarios donde han podido ponerse a prueba, la salud pública requiere acciones mucho más allá de la ciencia o la técnica, y un marco de decisión y gestión política (la cual es hoy prácticamente ausente), si se piensa en la racionalidad esencialmente económica que impera desde hace un tiempo desde la globalización de los mercados financieros y los tratados de libre comercio entre países desarrollados y no, de los cuales usualmente se benefician mucho más los primeros.

Iván Illich, en el prólogo de Némesis Medica (1975), dice que "salud es, después de todo, una palabra cotidiana que se usa para designar la intensidad con que los individuos hacen frente a sus estados internos y a sus condiciones ambientales" (p. 9). Así, no la restringe a un estado saludable como se promulga en la definición de la OMS, sino que tiene una dinámica que no depende únicamente del individuo. Continúa Illich (1975) diciendo:

En el Homo sapiens, "saludable" es un adjetivo que califica acciones éticas y políticas [...] Al menos, en parte, la salud de una población depende de la forma en que las acciones políticas condicionan el medio y crean aquellas circunstancias que favorecen la confianza en sí mismo, la autonomía y la dignidad para todos, incluidos los débiles y vulnerables. (p. 7)
Así, este autor concluye que los niveles de salud serán óptimos cuando se propicie que el individuo pueda desarrollar una capacidad de enfrentamiento autónoma, personal y responsable.

Oculta en uno de los capítulos de un texto de la Organización Panamericana de la Salud (OPS), hay una visión de salud que pareciera no interesar a nadie: "magnitud en que un individuo o grupo pueden, por una parte, realizar sus aspiraciones y satisfacer sus necesidades y por otra, cambiar su entorno o afrontarlo" (Kickbusch, 1996, p. 16). Esta visión se complementa muy bien con lo referido por Ivan Illich, por cuanto muestra el papel activo, de protagonista, de un ser humano. Adicionalmente, ese cambiar su entorno o afrontarlo invita, a las claras, a la participación política o social. La salud no es un fin en sí misma, es un medio que permitirá a cada uno de los seres humanos manifestar todo el potencial transformador con que venimos a la vida, no alguien que viene a recibir lo que otros tengan la voluntad de darle. Implícita, hay ahí una perspectiva de dignidad de los seres humanos, no importa en qué parte del planeta hayamos venido a parar, si por obra del amor o del azar (icasi lo mismo!). El punto es que aquí estamos y muchos seguimos pensando que cualquier injusticia contra un solo ser humano en cualquier lugar del mundo es una que se comete contra la humanidad entera, por tanto, nos indigna.

Volviendo a Musgrove y su visión según el artículo de difusión al que se hizo referencia en el primer párrafo de este escrito, el asunto es relativamente sencillo: si establecemos cuál es el problema prioritario, cuál el más costo efectivo y cuál o cuáles las intervenciones más adecuadas, estaríamos muy cerca de lograr la equidad en salud. Esta, claramente expues- 
ta, es la visión experta que, en el campo de la bioética clínica, correspondería a la perspectiva del bien, vista desde el profesional de salud. Desde la perspectiva anglosajona de la bioética, el paternalismo es beneficencia sin autonomía. Sin embargo, los dos principios terminan relacionándose con lo justo, pues hacer el bien desde la perspectiva del experto, sin considerar la del lego, puede resultar una injusticia. El experto reconocerá la postura del lego y este tendrá participación o representación en el ejercicio profesional. El paternalismo, en consecuencia, parecería también una perspectiva de lo justo desde arriba. Esa perspectiva es hoy inaceptable dentro de los hospitales y los centros de investigación, donde la bioética nació y se sigue desarrollando. La estrategia de reducción de inequidades de la OMS y la OPS se puede ver como la búsqueda de la justicia en salud desde arriba. Como mirada de justicia, debería ser ventilada por fuera de los organismos rectores de la salud en el mundo, los hospitales y los centros de investigación, para ampliar el campo de la bioética y dirigirla a la toma de decisiones en aquello denominado la política pública.

Sin embargo, acciones o programas tendientes a buscar justicia social que pretendan solamente distribuir, sin considerar el reconocimiento y la representación, si bien necesarias ante la demostrada inequidad en salud, educación, ingresos, etc., lucen insuficientes, mucho más cuando se pretende ahondar en democracia. El reconocimiento del otro como sujeto, como interlocutor válido, no es solamente aplicable a pacientes o sujetos de investigación vistos como individuos, se requiere reconocimiento de la otra cultura, de la otra forma de organización social, de todas aquellas minorías que hoy no tienen a quién decir nada porque nadie las quiere escuchar. En una perspecti- va más amplia, todos los pueblos del mundo son interlocutores válidos, pueblos dignos de consideración y respeto, fines en sí mismos, no más medios. La inequidad en salud que impera hoy en el globo supera los alcances de la epidemiología, la economía y la salud pública juntas. Aun en perspectiva de derechos humanos, pareciera que donde más lejos puede llegarse en bioética es al derecho a la atención en salud, es decir, acceso a la prestación de un servicio. Pero ni siquiera eso depende de acciones individuales, pues exige sobre todo; el ejercicio del poder público, es un asunto político, que atañe a toda la sociedad y al Estado, pues no va a solucionarse por sí solo abriendo más mercados ni firmando más tratados de comercio, y tampoco acogiendo más inversión extranjera.

Si a nivel individual debe contemplarse la perspectiva del bien, tanto desde el profesional de la salud o el investigador, como desde el paciente o el sujeto de investigación, a fin de tomar decisiones consensuadas, ¿es que no pueden tomarse decisiones consensuadas en los escenarios por excelencia colectivos de la salud pública, en aras del bienestar y la equidad?, ¿es que en estos escenarios estamos obligados a imponer nuestra visión experta?

La justicia social es una cuestión de vida o muerte. Afecta al modo en que vive la gente, a la probabilidad de enfermar y al riesgo de morir de forma prematura. Vemos maravillados cómo la esperanza de vida y el estado de salud mejoran de forma constante en algunas partes del mundo, mientras nos alarmamos ante el hecho de que eso no ocurra en otros lugares. (OMS, 2009, p. 3)

Si es un asunto de vida, atañe a la bioética porque cabe entre los temas alfa o beta, si es uno de muerte tiene que ver con los te- 
mas omega (Hottois, 2011); por tanto, la bioética no puede dejar por fuera aquello de los determinantes sociales de salud para dedicarse por entero a los dilemas en la relación médico-paciente o investigador-sujeto de investigación, así sea necesario seguir haciéndolo. Una bioética social debería, lógicamente, abordar asuntos sociales más que individuales, ahondar en la determinación social de las actitudes y comportamientos individuales, tanto como colectivos, ante los avances de la ciencia o la técnica a la luz de principios y valores humanos. Una bioética social, sin duda, requeriría la observación directa y aun la participación de los bioeticistas en movimientos sociales que justamente surgen a raíz de la brutal embestida de esta cultura, ya universal, de la rentabilidad, la compra y la venta, la del "vértigo de la producción, el culto a la competitividad y la celeridad de las operaciones económicas [que] van de la mano con la religión del consumo" (Breilh, 2001, p. 30).

Esos movimientos muestran cómo se superan conflictos entre representantes de diversas visiones en lo político, lo religioso o lo cultural; se buscan consensos, se participa activamente desde la experticia o la ignorancia, y se pone en práctica la interdisciplinaridad y aun la transdisciplinaridad en la toma de decisiones. En el interior de estos movimientos, hay formas de democracia y de pluralismo que no hemos explorado y quizá abran nuestros ojos a otras formas de organización y gobierno.

Los movimientos sociales están en el origen de la bioética y ella misma ha sido considerada por Fernando Lolas (1999, p. 15), aunque parado en una perspectiva esencialmente clínica de bioética, como un movimiento social en busca de reconocimiento; sin embargo, pareciera que lo hemos olvidado. Los ejemplos abundan en la historia de este saber recientemente fundado: la lucha contra la discriminación racial, la lucha por los derechos de los pacientes o por el derecho de las mujeres a decidir si tener o no hijos con sus parejas y cuántos, la lucha contra la estigmatización y la discriminación de homosexuales y por su derecho a participar o ser representados en los organismos de Gobierno fueron emprendidas en Estados Unidos por movimientos sociales que fueron creciendo hasta conseguir sus propósitos. Por qué los movimientos sociales han dejado de ser objeto de interés por parte de la bioética y los bioeticistas es un asunto que sobrepasa el propósito del presente escrito.

Para la Comisión sobre Determinantes Sociales de la Salud (CDSS) y la OMS habría tres recomendaciones generales para los países: 1) mejorar las condiciones de vida; 2) luchar contra la distribución desigual del poder, el dinero y los recursos, y 3) medir la magnitud del problema, analizarlo y evaluar los efectos de las intervenciones. Desde nuestra perspectiva, aunque sin límites netos entre uno y otro, el primero es un asunto fundamentalmente social; el segundo, uno esencialmente económico-político, y el tercero, uno básicamente científico-técnico. El punto es que todo eso deberá hacerse junto, si se quiere lograr aquello llamado justicia social y alcanzar las metas planteadas en el lapso de una generación, simplemente no será posible, es decir, quizá no haya tiempo suficiente para implementar semejantes cambios bajo el totalitarismo del mercado. Pareciera que debemos resignarnos a seguir midiendo y analizando la magnitud de los problemas, dado que el mundo sigue empeñado en desatender las condiciones de vida de los seres humanos y pocas oportunida- 
des hay de ganar esa lucha contra la distribución desigual del poder, el dinero y los recursos. Prueba de ello es que los Gobiernos de los países en crisis siguen empeñados en que los bancos deben ser apoyados con los pocos recursos disponibles, luego de haber vendido al mejor postor todo o casi todo lo público, aduciendo su ineficacia, ineficiencia y poca o ninguna efectividad.

\section{La dignidad desde otra mirada}

El enfoque utilitarista y economicista de la atención en salud propone mayores brechas de inequidad, que polarizan el acceso de los usuarios entre gastar e invertir en salud; esto es, pagar con antelación o pagar por el servicio de inmediato. Estas situaciones han llevado a que el derecho a la salud se convierta en mercancía y que la dignidad humana y la justicia social hagan parte de un imaginario de universales, que cada vez pierden mayor fuerza argumentativa y prescriptiva. Por esto es importante lograr identificar los límites conceptuales y axiológicos entre la calidad de vida y el bienestar humano, con el fin de proponer la "juridificación de la salud", porque se trata de un derecho fundamental, para que el Estado cumpla con los deberes que le corresponden frente a quienes son titulares de derechos (Consejo de Europa y Organización Panamericana de la Salud, 1999).

En este aparte se argumenta sobre los límites entre los términos calidad de vida y bienestar, mediados por el concepto de salud como obligación y como derecho. Se critica el modelo de Amartya Sen (1984) en orden a las capacidades y funciones, para proponer el modelo del Estado de bienestar, propio de las democracias parlamentarias, situado en la línea triple de opulencia, calidad de vida y bienestar.
En 1948, la OMS ${ }^{6}$ definió el término salud como un estado de completo bienestar físico, mental y social, y no solamente como la afección de enfermedades. Desde esa fecha, los instrumentos para evaluar la salud han sido insuficientes, esto es, los índices biológicos, clínicos y anatómicos (Guzmán, 2010).

Con el transcurrir del tiempo, se fue incorporando al término de salud el de la calidad de vida y a la vez se fue distanciando de las medidas clínicas biológicas y epidemiológicas e incluyendo apreciaciones subjetivas de los individuos para conocer la percepción de su propia salud. Es por esto que la OMS en 1994 definió la calidad de vida como la percepción del individuo sobre su posición en la vida, dentro del contexto cultural y su sistema de valores, proyectos, normas y preocupaciones.

Un acercamiento conceptual a la calidad de vida es insuficiente para nombrarse por medio de indicadores contemporáneos como ingreso bruto, ingreso per cápita, habitantes por metro cuadrado. Estos aspectos son mínimos y panorámicos para garantizar el pleno desarrollo de las personas en aspectos tan importantes, como la autoestima, dimensión relacional, la autonomía y la auto-ealización personal, entre otros; así lo señala Amartya Sen (1987, p. 55). Así que, de frente a la calidad de vida, es necesario identificar los estados de opulencia, tiempo libre y capacidad de elección.

Con todo, la OMS aprueba la medición de la calidad de vida con escalas a través de diferentes instrumentos, entre los cuales el Medi-

6 El Preámbulo de la Carta Fundacional de la OMS consagra un derecho básico de toda persona de gozar de elevados niveles de salud; es uno de los derechos fundamentales de cada ser humano, sin distinción de raza, religión, credo político, condición social o económica, lo que contribuyó a plasmar un nuevo enfoque y, más aún, un nuevo paradigma de salud. 
cal Outcomes Study Short Form (MOSSF-36) presenta un aceptado desarrollo psicométrico de confiabilidad, siendo el más estudiado y validado a nivel mundial, que aborda la calidad de vida en ocho dimensiones: dolor corporal, desempeño emocional, desempeño físico, función física, función social, salud general, salud mental y vitalidad.

A pesar de la pertinencia del estudio de la calidad de vida con instrumentos preestablecidos, este resulta incompleto, en la medida que desvirtúa los aspectos históricos, culturales y sociales, y olvida que "los actores que se estudian son portadores de perspectivas e interpretaciones de sí mismos, y de sus acciones sociales" (Galeano, 2004, p. 45).

Por tanto, la calidad de vida es la percepción del individuo sobre su vida, el lugar que ocupa en su contexto cultural y sistema de valores, la relación con sus objetivos, expectativas y normas; todo ello permeado por las actividades diarias, la salud física, el estado psicológico, el grado de independencia, las relaciones sociales, los factores ambientales y las creencias personales. La calidad de vida relacionada con la salud constituye el valor asignado al tiempo de vida y los cambios que se producen en la calidad de vida debido a la enfermedad, los tratamientos, las lesiones o discapacidades (Patrick y Erickson, 1993).

Por lo anterior, resulta relevante trascender los resultados de los instrumentos de evaluación de la calidad de vida, a partir de abordajes hermenéuticos que den cuenta de los conocimientos y experiencias acumuladas. Además, el abordaje multidimensional de la calidad de vida permite focalizar necesidades, orientar la formulación o implementación de medidas de salud pública, desarrollar y evaluar modelos de atención en salud y describir aspectos de la cotidianidad.
Según los resultados de una investigación realizada en 2009 en Medellín, Colombia, sobre la calidad de vida de pacientes con VIH (Higuita y Cardona, 2009), algunos de los encuestados afirmaban: "Salud es no estar postrado en una cama", "salud es no tener alteraciones físicas ni dolor" (Higuita y Cardona, 2009, p. 57). Otros toman la salud como sinónimo de calidad de vida, aludiendo una visión holística de ambas, por cuanto integran aspectos como empleo, vivienda, alimentación, recreación, afecto, asistencia en salud, educación y entorno saludable.

Según Ardila (2003), la calidad de vida es un estado de satisfacción general, derivado de la realización de las potencialidades de la persona. Posee aspectos subjetivos y objetivos. Es una sensación subjetiva de bienestar físico, psicológico y social. Incluye como aspectos subjetivos la intimidad, la expresión emocional, la seguridad percibida, la productividad personal y la salud objetiva, y como aspectos objetivos, el bienestar material, las relaciones armónicas con el ambiente físico y social y con la comunidad, y la salud objetivamente percibida.

La medición de la calidad de vida presenta retos metodológicos que se han venido resolviendo, y que han permitido desarrollar instrumentos aplicables a diversas enfermedades y poblaciones. Los problemas metodológicos que enfrenta la medición de calidad de vida son dos: primero, que se trata de medidas consideradas "blandas" y, segundo, que no hay un valor de referencia o "estándar de oro" contra el cual se pueda comparar. Las dos pruebas más importantes a las cuales deben someterse estas mediciones son las de validez y consistencia; una vez que cumplan estos atributos podrá aceptarse que las mediciones tengan calidad científica. Es decir, si 
los instrumentos miden realmente lo que se quiere medir y si esta medición es consistentemente reproducible por el mismo observador o por otros. Actualmente, se cuenta con dos tipos de instrumentos: los genéricos, que permiten evaluar grupos y poblaciones con diversos diagnósticos, y los específicos, que son de mayor utilidad para medir el impacto de una enfermedad específica. Los instrumentos disponibles actualmente para medir la calidad de vida son confiables y constituyen una herramienta complementaria para evaluar la respuesta al tratamiento.

Estos instrumentos también han sido evaluados en función de su capacidad de discriminación, descripción y predicción de la calidad de vida. Finalmente, hay que reconocer que la mayoría de los instrumentos disponibles han sido desarrollados en inglés; por tanto, su aplicación en países de habla hispana requiere métodos de traducción válidos, así como reconocer que son específicos al contexto social, es decir, se debe asegurar que los dominios explorados sean apropiados para la población donde se van a implantar. Amartya Sen (1987) sugiere que es necesario rechazar el concepto de utilidad para efectos de proponer un criterio para la evaluación de la calidad de vida. Se trata de tres maneras diferentes de concebir la utilidad humana: placer y felicidad, satisfacción de los deseos y elección del mejor bien.

En cuanto al placer, Sen (1984) expone de manera directa que una persona pobre, explotada y enferma podría estar complacida con su presente, esto tal vez motivada por los múltiples condicionamientos sociales que le sobrepasan. Esto, por cuanto el nivel de la calidad de vida no podría estar distanciado de la vida real que es menester vivir, por lo que siempre se espera una oportunidad en ganancia extra, una rifa, un juego o encontrarse un tesoro. Sobre el imperativo de la satisfacción de los deseos, es también necesario identificar, como lo expone Sen (1987), que se trata de una dialéctica agresiva entre la ausencia de esperanza y el temor al desengaño, que lo uno y lo otro provocaría la extinción de todo deseo. ${ }^{7}$ El pobre se reconcilia con las desigualdades sociales, ajusta sus deseos a sus posibilidades, no se interesa ni lucha por la equidad. En cuanto a la posibilidad de elección, Sen (1984) la identifica con reflejo de los deseos, que responden a motivaciones complejas y no siempre están orientadas al bienestar. El autor critica el concepto de utilidad como único criterio para evaluar la calidad de vida por sus fuertes componentes subjetivos que afectan, según él, la ponderación y el cálculo. En cambio, la opulencia y el tiempo libre son categorías más objetivas Sen (1887). También podría pensarse una persona muy opulenta y sin bienestar, aunque sí con un buen nivel de vida. Difícilmente una persona pobre tendría buen nivel de vida, aunque pudiera darse el caso que tenga bienestar.

Con todo, el modelo de Sen (1984) fue concebido inicialmente para dar cuenta del bienestar y fue extendido luego para evaluar la calidad de vida, como si ambos conceptos fueran lo mismo. La debilidad del modelo de Sen (1984) es su relación entre la opulencia, las capacidades y funciones. La realidad es que la opulencia probablemente determinaría las capacidades del individuo y, por tanto, la relación entre las capacidades y funciones. Así, el nivel de vida queda del todo determinado por la opulencia. El problema está en extrapolar características del bienestar a la calidad de vida. Esta

$7 \quad$ El budismo enseña que la vida es sufrimiento, ese sufrimiento fue causado por el deseo, y hay que superar el deseo para obtener la paz y la felicidad. 
última es un concepto de gran importancia para los Gobiernos contemporáneos, a fin de medir su éxito o su fracaso en políticas públicas. Las colectividades humanas hoy, en la cultura occidental, estamos acostumbrados a escuchar a los medios de opinión presentando posibilidades de mejora por la acción estatal; con frecuencia se anuncia que baja el desempleo drásticamente y con esto sube la calidad de vida, pero la realidad de las grandes ciudades suele ser dramática y ni qué decir de lo rural en los países denominados en vías de desarrollo.

El caso de la salud es aún más dramático. Si para evaluar la calidad de vida se miden los estándares en salud, con dinero y sin dinero, el grado de opulencia tendría un efecto mayor. Es por esto que cuando la salud cuenta para el nivel de vida se reduce a términos de opulencia. Con todo, Sen (1987) identifica que las diferencias entre las capacidades y la opulencia son el aparecimiento en público sin vergüenza, situación que nada tiene que ver con la calidad de vida.

La propuesta de Sen (1984) se fundamenta en una crítica al utilitarismo por el empleo de criterios subjetivos de evaluación y pretende basarse en criterios objetivos, pero la vergüenza es subjetiva. El criterio de funciones y capacidades no es posible para hacer referencia al bienestar y a la calidad de vida. La realidad nos desborda, por tanto, los niveles de opulencia proveen también los niveles de calidad de vida y de bienestar. Según Sen (1987), la opulencia está relacionada con capacidades y funciones y esto con el bienestar, pero no con la calidad de vida. De tal manera que los únicos criterios para medir el bienestar y la calidad de vida son la opulencia y el tiempo libre.
Para evaluar la calidad de vida y el bienestar de las personas, es importante la identificación del concepto de salud como medio fundamental. La salud es una realidad que expresa de forma peculiar y auténtica la más profunda axiología del hombre, pues sus límites son la enfermedad y la muerte. Así, vida y salud son la expresión de una misma realidad por su profunda correspondencia, por tanto, sin un mínimo de salud se va perdiendo en vida, y sin vida, no hay salud. Ontológicamente, la salud es el ser del viviente y se expresa armónicamente por medio de todas las potencializaciones físicas y mentales del individuo mediante el ejercicio de su memoria, inteligencia y voluntad. La salud es más que un bienestar, es un bien ser, es la manifestación axiológica, entre la antigua dupla de psique y soma, que aparece como expresión de un acto ético, con repercusión jurídica, que supera lo mínimo de la prescripción biológica y está en constante búsqueda de su plenitud vital.

La OMS ha definido la calidad de vida como "la percepción que un individuo tiene de su lugar en la existencia, en el contexto de la cultura y del sistema de valores en los que vive y en relación con sus expectativas, sus normas, sus inquietudes" (The World Health Organization Quality of Life, 1996). Este concepto es multidimensional y se compone no solo de la salud de un individuo, sino también de múltiples aspectos no relacionados con problemas médicos, tales como el nivel socioeconómico, el estado civil, la carrera profesional, la personalidad, la felicidad, la ambición, las expectativas de un individuo y sus aspectos religiosos. Así es como cada vez cobra más importancia esa relación entorno-individuo, en la medida en que aumenta más la frecuencia de enfermedades crónicas, la de personas 
con algún grado de discapacidad, o simplemente en la medida en que se incrementa la preocupación y el cuidado del cuerpo del individuo que tiene la necesidad natural de ajustar su apariencia a la de aquellos con los cuales convive para no sentirse excluido.

Adicionalmente, la autoimagen, constituye un elemento esencial en la estructura de la personalidad que no solo afecta la salud mental, sino también la actitud hacia el entorno (Potocka y Turczyn, 2008). Se ha descrito que la autoimagen es un predictor de la satisfacción general y por lo tanto afecta de forma importante la calidad de vida (Schimmack, RadhaKrishnan, Oishi, Dzokoto y Ahadi, 2002). De hecho, una autoimagen favorable lleva a emociones favorables, mientras que una autoimagen desfavorable da lugar a ansiedad, temor, ira, depresión y desadaptación social. Por otra parte, se sabe que una persona con determinada enfermedad no solo debe convivir con sus propias emociones, sino además con las restricciones que se le imponen en su vida familiar, social y laboral. Es así como debido a que, en muchas ocasiones, la enfermedad altera la apariencia personal, tiene un gran papel en el desarrollo de trastornos psicológicos.

Ahora bien, si la salud incide favorablemente en la medición de la calidad de vida, es pues urgente y necesario defender y promover su juridificación, la cual consiste en su reconocimiento como un derecho fundamental, porque es inherente a la dignidad de la persona. Es también, por tanto, un derecho derivado de la vida, pues es evidente la conexidad entre el derecho a la vida y a la salud (Hervada, 1986, p. 232). Por tanto, es, asimismo, un derecho que implica conservación, restablecimiento y autocuidado.

\section{¿Conclusiones?}

No parece posible ni sensato concluir a este respecto (la equidad), por eso los signos de interrogación. Sin embargo, es necesario referir que la dignidad, así sea uno de los varios indefinibles con que nos topamos a menudo en bioética o filosofía, parece haber quedado por fuera de la racionalidad que hoy guía los destinos de las sociedades: la económica. Los asuntos de justicia tocan de lleno la dignidad de los seres humanos, por cuanto ella nos hace iguales a pesar del color diferente de nuestras pieles, la consideración del bien o del mal por la que nos inclinemos en el interior de las culturas donde nacemos y crecemos, las vertientes políticas por las que nos deslicemos, el nivel educativo o el tipo de trabajo que desempeñemos, etc.

La consideración de lo justo parece superar el alcance de la estrategia de búsqueda y reducción de inequidades en salud con la que opera hoy la OMS, esperanzada en que la ciencia y la tecnología darán solución a la falta de justicia social cada vez más evidente y en pleno crecimiento. La ciencia y la técnica por sí mismas no harán justicia, esta última requiere ética y política puestas de un mismo lado, es decir, juntas y revueltas, para que no sean la eficacia, la efectividad o la eficiencia los únicos criterios que consideren los Gobiernos al momento de tomar decisiones. Sin duda, se necesita de un conocimiento recombinante, ${ }^{8}$ esto es, inter y transdis-

8 Escuchamos esta expresión de boca de Carlos Delgado, filósofo cubano, conocedor de la teoría de la complejidad y quien visitó nuestro país cuando cursábamos la fase presencial del programa de doctorado en Bioética en la Universidad El Bosque. El conocimiento recombinante, como concepto, era para él fundamental si de veras se sostiene que la bioética es un saber transdisciplinario. En la perspectiva de VR Potter estaba implícito un tipo de conocimiento como este, mucho 
ciplinar, para abordar posibles soluciones a los más grandes desafíos a los que nos vemos enfrentados en materia de justicia social. Una salud pública concentrada en los riesgos y las diferencias o las razones de riesgos puede ser necesaria, pero claramente no basta, al igual que una bioética encerrada en los hospitales o los centros de investigación.

Es necesario retomar lo social tanto en la epidemiología como en la bioética, por cuanto estuvo presente en sus orígenes aunque lo fuimos haciendo a un lado conforme la cultura del individualismo, la competencia y la renta fue erigiéndose como la única y más importante hacia el desarrollo y el progreso de los pueblos. El abordaje de los determinantes sociales de las condiciones de salud o enfermedad por parte de la epidemiología desde la visión de la OMS y la OPS es ya un avance en cuyos orígenes están también movimientos sociales por la salud pública en Latinoamérica y Europa, pero aún queda un largo trecho por recorrer. Lo que debe recorrerse exige la construcción de formas de democracia que no hemos vivido, pero que pudieran ponerse en práctica en el interior de los movimientos sociales, como este de los indignados en España, o el nacido en Portoalegre, Brasil hacia "otro mundo posible", los cuales han sobrepasado las fronteras de los países de origen y continúan avanzando. Pues bien, estos movimientos que son conformados por sujetos, como los descritos en aquella definición de salud a la que se hizo referencia unos párrafos atrás, están afrontando y tratan de cambiar su

más cercado a la sabiduría que el conocimiento disciplinar, mucho más amplio que en interdisciplinar y, sobre todo, uno que contempla los conocimientos no expertos en la mira de dar respuestas a los problemas más serios para la humanidad, entre ellos, la falta de justicia social, los daños al ambiente, la violencia generalizada, la guerra o la paz. entorno. Sin duda, a su interior deben surgir conflictos dada la diversidad de posturas religiosas, políticas, étnicas, ideológicas, en fin, y tales conflictos pueden ser abordados de maneras poco o nada conocidas entre quienes hemos trabajado en los comités de ética de la asistencia o de la investigación en la mira de encontrar soluciones. Es probable que en su interior se den formas de diálogo inter y transdisciplinar que puedan mostrarnos caminos en esa perspectiva, dado que tenemos grandes dificultades para entendernos unos a otros, así sea en este pequeño universo de lo académico en maestrías y doctorados. Baste mencionar, a manera de ejemplo, los choques entre quienes trabajamos metodologías cuantitativas y quienes trabajan métodos cualitativos en salud públi$\mathrm{ca}$, generalmente a partir de caricaturas a las cuales dirigimos verdaderas diatribas de las que finalmente nada queda. Por otro lado, el trabajo intersectorial requiere alianzas y quizá los movimientos sociales nos muestren formas más efectivas de hacerlas que el lobby o cosas por el estilo, las cuales en las llamadas democracias representativas parecen funcionar generalmente para los más poderosos de entre todos los que lo practican.

Que los bioeticistas salgamos del encierro de los comités asistenciales o de investigación con seres vivos, sean humanos o no, para nutrirnos de la riqueza que los movimientos sociales llevan por dentro en lo ético y lo político, quizá nos permita dar un perfil latinoamericano a esta interdisciplina científica que pareciera terminar sus días en los listados de normas de buenas prácticas clínicas o de investigación que, parafraseando a Eduardo Galeano en Memoria del Fuego, aunque rascan y puede ser que rasquen bien, siguen rascando donde no nos pica o donde menos nos pica. 


\section{Referencias}

Ardila, R. (2003). Calidad de vida: una definición integradora. Revista Latinoamericana de Psicología, 35(2), 163.

Barbosa, J., Azevedo Barros, M. (2002). Epidemiologia e desigualdade: notas sobre a teoría e a história. Pan American Journal of Public Health, 12(6), 375-383.

Breilh, J. (2001). Una perspectiva emancipadora de la investigación e incidencia basada en la determinación social de la salud. En C. Eibenschutz, S. Tamez, R. Gonzales (Comps.). ¿Determinación social o determinantes sociales de la salud? México, D. F.: Universidad Autónoma Metropolitana.

Consejo de Europa y Organización Panamericana de la Salud (OPS). (1999). La salud y los derechos humanos. Aspectos éticos y morales. Washington, D. C.: Organización Panamericana de la Salud [OPS].

Escobar López, M. T. y Carrera Celis, C. A. (2015). Percepción sobre consentimiento informado en pacientes de cuatro diferentes áreas de atención en salud en Bogotá Colombia. Revista Latinoamericana de Bioética, 15(289, 14-25.

Escobar López, M. T. y Novoa Torres, E. (2016). Análisis de formatos de consentimiento informado en Colombia. Problemas ético-legales y dificultades en el lenguaje. Revista Latinoamericana de Bioética, 16(1), 14-37.

Evans, R., Barer, M. y Marmor, T. (1996). ¿Por qué una gente está sana y otra no? Madrid: Diaz de Santos.

Fraser, N. (2008). Escalas de justicia. Barcelona: Herder.
Galeano, M. (2004). Estrategias de innovación social cualitativa. Medellín: La Carreta.

Gómez, R. (2008). La dignidad humana en el proceso salud- enfermedad. Bogotá: Editorial Universidad del Rosario.

González, J. (2008). Dignidad humana. Diccionario Latinoamericano de Bioética. Bogotá: Red bioética Unesco, Universidad Nacional de Colombia.

Gosta, E., Duncan, G., Hemericjck, A. y Myles, J. (2006). Por qué necesitamos de un nuevo Estado benefactor. México: McGraw-Hill

Guzmán, C. (2010). Calidad de vida relacionada con la salud de los enfermos con cardiopatía. Revista de Cardiología, 16(2.), 171-176.

Hervada, J. (1986). Los trasplantes de órganos y el derecho a disponer del propio cuerpo. En Escritos de derecho natural (209315). Pamplona: Eunsa, Ediciones Universidad de Navarra.

Hernández, L. (2003). ¿Qué es la salud pública basada en la evidencia? Revista Salud Pública, 5(1), 40-45.

Higuita, L. y Cardona, J. (2009). Calidad de vida en personas con VIH/SIDA, pertenecientes a una organización no gubernamental. Medellín: Escuela de Microbiología de la Universidad de Antioquia.

Hottois, G. (2011). Definir la bioética: retorno a los orígenes. Revista Colombiana de Bioética, 6(2), 62-85.

Illich, I. (1975). Némesis médica. La expropiación de la salud. Breve Biblioteca de Respuesta. México, D. F.: Seix Barral. 
Kickbusch, I. (1996). Promoción de la salud: una perspectiva mundial. En Promoción de la salud: una antología. Washington: Organización Panamericana de la Salud [OPS], Organización Mundial de la Saludo [OMS].

Lolas, F. (1999). Temas de bioética. Santiago de Chile: Editorial Universitaria.

Mokate, K. (2002). Eficacia, eficiencia, equidad y sostenibilidad: ¿Qué queremos decir? Recuperado de https://www.cepal. org/ilpes/noticias/paginas/9/37779/gover_2006_03_eficacia_eficiencia.pdf

Musgrove, P. (2006). Inversión para el bienestar: ¿cuánta salud puede comprar un dólar? Ciencia \& Trabajo, 8(20).

Organización Mundial de la Saludo (OMS), Comisión sobre Determinantes Sociales de la Salud. (2009). Informe Final. Subsanar las desigualdades en una generación. Alcanzar la equidad sanitaria actuando sobre los determinantes sociales de la salud. Buenos Aires: autor.

Patrick, D. y Erickson, P. (1993). Health status and health policy: Quality of life in health evaluation and resource allocation. Nueva York: Oxford.

Pelè, A. (2005). Una aproximación al concepto de dignidad humana. Revista Universitas, (1), 9-13.

Potocka, A. y Turczyn, M. (2008). Self - image and quality of life of dermatology patients. Occupational Medicine and Environmental Health, 21(4), 309-317.

Rodríguez del Pozo, P. (1998). El objeto de la justicia sanitaria. Bioética y derechos humanos. Bogotá: Ediciones El Bosque.
Sáenz Cortés, M., Escobar López, M. T. y Aristizábal Tobler, Ch. C. (2016). Los menores y adolescentes en la investigación clínica. Tensiones y aspectos éticos. Escritos, 24(53), 319- 344.

Schimmack, U., Radhakrishnan, P., Oishi, S., Dzokoto, V. y Ahadi, S. (2002). Culture, personality, and subjective well-being: integrating process models of life satisfaction. Journal of Personality and Social Psychology, 82(4), 583-93.

Sen, A. (1987). The Standard of Living. Londres: Cambridge University Press.

Sen, A. (1984). Well - Being, Agency and Freedom. The Journal of Philosophy, LXXXII(4), 169-221.

The World Health Organization Quality of Life. (1996). Assessment Instrument. En Bert Spilker (Ed.), Quality of Life and Pharmacoeconomics un Clinical Trials (pp. 355-62). NuevaYork: Lippincott- Raven.

Tujan, A. (2007). ¿Reducir la pobreza o edulcorar la globalización neoliberal? ¿Objetivos de desarrollo del milenio? La Habana: Editorial de Ciencias Sociales.

Vial- Correa, J. y Rodríguez- Guerrero. (2009). La dignidad de la persona humana. Desde la fecundación hasta la muerte. Acta Bioética, 15(1), 55-64.

Whitehead, M. (1992). The concepts and the principles of inequity in health. International Journal of Health Services, 22(3), 429-445. 